\title{
EDUCAÇÃO SOMÁTICA E DANÇA NA CONSCIÊNCIA CORPORAL
}

\author{
Nicole Rosa Cachoeira \\ Universidade Federal de Santa Catarina, Santa Catarina, Florianópolis, Brasil \\ Luciana Fiamoncini \\ Universidade Federal de Santa Catarina, Santa Catarina, Florianópolis, Brasil
}

\begin{abstract}
Resumo
Este trabalho tem como objetivo descrever como a educação somática e a dança podem proporcionar o desenvolvimento da consciência corporal dos participantes do projeto de extensão Vivências Corporais Lúdicas. Este estudo se caracteriza por uma pesquisa exploratória com abordagem qualitativa, na qual foram utilizados como instrumentos o diário de campo e a entrevista semiestruturada. A interpretação dos dados foi por meio da Análise de Conteúdo (BARDIN, 2009). O estudo apontou que as vivências de educação somática despertaram nos participantes a sensação de relaxamento, relacionada ao alívio de tensões e dores, proporcionando um estado perceptivo e integral das dimensões corporais. Em relação à dança destacam-se a improvisação, a socialização, sentimento de prazer e ludicidade.
\end{abstract}

Palavras-chave: Corpo. Dança. Estado de Consciência.

\section{SOMATIC EDUCATION AND DANCE IN BODY AWARENESS}

\begin{abstract}
This work aims to describe how the somatic education and dance can provide the development of the corporal consciousness of the participants of the extension project entitled Vivências Corporais Lúdicas. This study is characterized by an exploratory research with a qualitative approach, in which the field journal and the semi-structured interview were used as instruments. The interpretation of the data was through the Content Analysis (BARDIN, 2009). The study pointed out that the somatic education experiences awakened in the participants the sensation of relaxation, related to the relief of tensions and pain, providing a perceptive and integral state of the body dimensions. In relation to the dance, it highlights improvisation, socialization and feelings of pleasure and playfulness.
\end{abstract}

Keywords: Body. Dance. State of Consciousness.

\section{LA EDUCACIÓN SOMÁTICA Y DANZA EN EL CONOCIMIENTO DEL CUERPO}

\section{Resumen}

Este documento tiene por objeto describir cómo la educación somática y la danza pueden proporcionar el desarrollo de la conciencia corporal de los participantes del proyecto de ampliación Vivências Corporais Lúdicas. Este estudio se caracteriza por una investigación exploratoria con enfoque cualitativo, en la cuel fue utilizado como instrumentos el diario de campo y 
semi-estructurada entrevista. La interpretación de los datos fue a través del Análisis de Contenido (BARDIN, 2009). El estudio encontró que las experiencias de educación somáticas desperto en los participantes una sensación de relajación, relacionados con el estrés aliviar el dolor y proporcionar un estado perceptivo y completa de las dimensiones corporales. En cuanto a la improvisación de danza destaca, socialización, sensación de placer y alegría.

Palabras clave: Cuerpo. Danza. Estado de conciencia.

\section{Introdução}

Vivemos em uma realidade em que o corpo é valorizado por meio de sua aparência física, a eterna busca pela beleza exterior, que é imposta muitas vezes pela mídia, como um modelo a ser seguido, influenciando os valores e os costumes da sociedade (FREIRE; DANTAS, 2012). Os aspectos sensitivos e emocionais são deixados de lado, a individualidade de cada ser humano e a busca por sua autenticidade acabam sendo desvalorizadas em uma sociedade que prioriza a padronização de movimentos, pensamentos e ações. Diante dessa realidade, a maioria dos estabelecimentos que oferecem práticas corporais abordam os movimentos corporais de uma maneira fragmentada, mecânica e repetitiva, tratando o corpo como mero objeto (BONETTI, 2006).

A possibilidade de um corpo sensível, nesses programas, baseado na consciência do mesmo, e não em uma disciplina imposta e padronizada (BONFIM, 2002), fica muito reduzi$\mathrm{da}$, pois as pessoas esquecem, muitas vezes, de sentir o movimento em si, de sentir as articulações, os ossos e os músculos agindo em uma sinergia única, em um sistema integrado. Além disso, esses programas não propõem a criatividade, o que não contribui para o desenvolvimento de um corpo espontâneo, criativo e consciente, provocando, muitas vezes, a pouca motivação dos participantes nas aulas.

A anestesia das sensações ou "dessensibilização" é um fenômeno cada vez mais frequente nas sociedades urbanas (IMBASSAÍ, 2003), em que prevalece uma cultura altamente produtiva e competitiva, trazendo como consequências: fadiga, estresse, ansiedade, insônia, dores de cabeça, depressão, dentre outras. Dessa forma, com a vida cotidiana conturbada e o excessivo acúmulo de tarefas e informações, acabamos não sentindo ou sentindo em excesso, contribuindo para uma espécie de anestesia ao movimento, ou seja, "a negação do sensível ou a incapacidade do sentir" (MILLER, 2012, p. 105).

A possibilidade de um anestesiamento dos sentidos mostrou-se pertinente a partir do campo em que se desenvolveu essa pesquisa. Outras abordagens sobre o tema podem ser realizadas, porém, nesse estudo, o contexto encontrado mostrou corresponder com a perspectiva desenvolvida. Dessa forma, a sensibilidade abordada neste trabalho está relacionada com a vivência particular, subjetiva que cada pessoa obtém no contato e conexão com seus sentidos, sensações e percepções. E, como refere-se Fiamoncini (2015, p. 48),

[...] a sensibilidade se expressa nas palavras que se referem a momentos vividos em que somos levados à comoção pelo toque, pelo abraço, pelo respeito, pelo afago, proporcionados, recebidos ou retribuídos. Ante essa perspectiva, a intensidade da vida se dá a partir dos sentidos que atribuímos a ela, de modo que cada um pode sentir e compreender à sua maneira, a partir de suas relações e experiências com o outro, com o mundo da vida.

A consciência corporal ${ }^{1}$ está intimamente ligada à sensibilização, à percepção do corpo no espaço, à interioridade, à capacidade de silenciar o corpo e voltar a atenção para as suas

\footnotetext{
${ }^{1}$ Neste trabalho, consciência corporal diz respeito ao despertar sensorial do corpo, por meio da propriocepção, 
sensações. Nessa perspectiva, "a conscientização corporal acredita poder contribuir para a reversão desse fenômeno [anestesia das sensações] por meio de um aprofundamento da consciência de si, enquanto unidade somatopsíquica" (IMBASSAÍ, 2003, p. 50), priorizando a totalidade do ser humano, o estado de bem estar global da pessoa no ambiente.

Nesse contexto de sensibilidade e consciência corporal, a educação somática vem como "um campo teórico e prático que se interessa pela consciência do corpo e seu movimento" (BOLSANELLO, 2005, p. 100). A educação somática leva o aluno a despertar outros sentidos que são poucos desenvolvidos durante a nossa vida, como o tato e a sensibilidade da pele, a propriocepção, a audição, o olfato, e assim tornar o corpo perceptivo nas suas relações internas e externas. Nesse aspecto, a dança possui forte ligação com a educação somática por aproximar a pessoa de sua consciência corporal, por estimular a criatividade através de improvisações, e desenvolver a concentração de um corpo presente. Neste estudo, o foco está na atenção para o trabalho com a improvisação, o contato improvisação e a criatividade de movimento por meio da dança. Além disso, a dança pode proporcionar aspectos lúdicos, através da espontaneidade, do brincar com o corpo e experimentar novos caminhos através de movimentações livres.

Desse modo, o presente estudo teve como objetivo descrever como a educação somática e a dança podem proporcionar o desenvolvimento da consciência corporal dos participantes do projeto de extensão Vivências Corporais Lúdicas, da Universidade Federal de Santa Catarina (UFSC).

\section{Metodologia}

Este estudo se caracteriza por uma pesquisa exploratória com abordagem qualitativa que permite o aprofundamento entre a realidade objetiva e a subjetividade das pessoas, interagindo com a complexidade humana. Ele desenvolveu-se a partir do que se observou e evidenciou durante a ministração das aulas no projeto de extensão Vivências Corporais Lúdicas (VCL), do Centro de Desportos da UFSC.

Os sujeitos da pesquisa foram oito pessoas, sete do sexo feminino e um integrante do sexo masculino e, de acordo com a característica do projeto, a idade dos participantes é de 47 a 67 anos. A seleção dos sujeitos ${ }^{2}$ foi composta pelos seguintes critérios: estar inserido há pelo menos um ano no projeto Vivências Corporais Lúdicas e ter uma frequência assídua nas aulas.

Os instrumentos utilizados na coleta de dados foram a entrevista semiestruturada, para os alunos expressarem suas sensações, sentimentos, opiniões pessoais; e o diário de campo, em que foram registradas falas e situações observadas durante as aulas e que foram significativas a essa pesquisa.

Em relação às entrevistas foram realizadas oito perguntas, que abordaram como temas a consciência corporal, sua relação com a vida cotidiana dos participantes e as vivências do projeto. A educação somática e os elementos da dança foram outros temas abordados nas entrevistas, que buscaram a reflexão na maneira de perceber o corpo e se relacionar com o ambiente (sentimentos e sensações), e também possíveis mudanças corporais e socioafetivas que surgiram e influenciaram o estilo de vida das(o) entrevistadas(o) a partir das suas vivências no decorrer do projeto.

que traz à atenção de se perceber, "possibilita o estado ao vivo, ou seja, do corpo vivo, espontâneo e atento aos acontecimentos e sensações do tempo presente" (MILLER, 2007, p. 51).

2 Todos os participantes da pesquisa assinaram o Termo de Consentimento Livre Esclarecido (TCLE), observando a voluntariedade da participação e a confidencialidade dos dados obtidos. Este estudo foi aprovado pelo Comitê de Ética em Pesquisa da Universidade Federal de Santa Catarina, sob o número de registro 1.768.609. 
O diário de campo foi elaborado durante o semestre, de acordo com os relatos posteriores à prática realizada, "um procedimento em que os alunos são estimulados a mencionar a sensação que predominou no corpo depois da atividade" (TEIXEIRA, 2000, p. 73). Além disso, o diário visa registrar e caracterizar todas as observações em relação aos sentimentos, opiniões dos participantes sobre as dinâmicas realizadas. Dessa forma, o diário de campo conteve falas, sensações, atitudes, olhares, comportamentos.

A interpretação dos dados foi realizada por meio da Análise de Conteúdo de Bardin (2009). No primeiro momento da análise, houve a leitura do referencial teórico, em que foram identificadas as palavras-chave ou unidades de registro. Dessa maneira, as unidades de registro foram agrupadas constituindo algumas pré-categorias. Após esse procedimento, foi realizada a leitura do diário de campo e das entrevistas em que se identificaram as unidades de contexto ou unidades de significado, que são representativas das circunstâncias encontradas no referencial teórico e estão associadas a determinadas situações e contextos. Desta forma, as unidades representativas identificadas foram agrupadas e classificadas em um tema comum entre elas, elaborando-se, assim, as categorias.

A primeira categoria está relacionada com a sensibilidade e a educação somática, nomeada, a escuta do corpo e a escuta do outro. A segunda categoria está relacionada com a dança e os momentos mais significativos no projeto, nomeada, a dança da vida: "livre, leve e solto". Feita a categorização, iniciou-se a interpretação, a análise crítica e reflexiva de todo o material.

\section{Educação somática e a experimentação do corpo}

A educação somática é uma área de conhecimento que visa abordar o corpo enquanto experiência, a totalidade do ser humano; busca um estado de equilíbrio entre os aspectos físicos, psíquicos, sociais e a sua interação com o ambiente, proporcionando à pessoa a capacidade de se autorregular (BOLSANELLO, 2005). Thomas Hanna (1928 - 1990) é um dos pioneiros da educação somática e foi quem criou o termo somático (MARKONDES, 2008). Hanna foi quem distinguiu os conceitos entre corpo e soma; para ele, soma é o corpo visto em primeira pessoa, o corpo subjetivo em relação ao próprio indivíduo, como este sente o seu próprio corpo. Já a palavra corpo se relaciona com a terceira pessoa, com a observação vinda de fora, o corpo que é percebido (HANNA, 2003 apud BOLSANELLO, 2011). ${ }^{3}$ Nesse sentido, soma é vida, energia, pulsação, sensação, proporciona experiências corpóreas que geram adaptações no comportamento humano, soma e corpo se complementam, estão envolvidos no mesmo ambiente em um processo sinergético.

Nesse sentido, os profissionais que trabalham com a educação somática não possuem o objetivo de trabalhar somente o corpo, mas sim de proporcionar a experiência através do corpo (BOLSANELLO, 2005). Para os profissionais dessa área a saúde é um conjunto formado por diversos fatores, psíquicos, cognitivos, fisiológicos e afetivos que interagem em seu meio ambiente. Assim, nas aulas de somática busca-se um equilíbrio entre todos esses fatores que envolvem o ser humano, contemplando a sua totalidade. Neste estudo, a totalidade se refere ao conjunto das dimensões que contemplam o ser humano, como a dimensão física, emocional-afetiva, mental-espiritual e sócio-histórico-cultural (JOÃO; BRITO, 2004).

A principal ferramenta da educação somática é o trabalho com a sensibilidade, pois é por meio dela que conseguimos desenvolver a consciência corporal, estabelecendo uma conexão profunda com todos os órgãos sensoriais, silenciando o corpo para a percepção dos estímulos internos e externos que envolvem o ambiente no qual estamos inseridos.

\footnotetext{
${ }^{3}$ Esta divisão se encontra no uso do termo pela adequação de significado, de conteúdo, da origem latina do termo soma.
} 
Dessa forma, o trabalho a partir do tato é uma das maneiras que a educação somática disponibiliza para explorar a sensibilidade da pele, que é um dos canais de propriocepção que o nosso corpo disponibiliza. "O toque é a sensação mais primitiva do ser humano e é a primeira via senso-motora que os professores de educação somática abordam" (BOLSANELLO, 2005, p. 102-103). O toque estimula segmentos corporais nunca tocados antes, e fornece a troca de energia entre os seres humanos e materiais presentes no espaço; assim, através da pele é possível sentir a espessura, o formato e a profundidade dos elementos.

A dança e a educação somática possuem uma forte ligação por serem campos que trabalham com a sensibilização do corpo e com a criação de movimentos. Assim, muitos bailarinos e companhias de dança utilizam a educação somática como forma de desenvolver o refinamento sensorial, aumentar as possibilidades de escolha na movimentação e a liberdade de expressão. No Brasil, Klauss Vianna foi um dos primeiros a estudar a educação somática e sua aproximação com a dança, o que originou a técnica Klauss Vianna, baseada nos princípios somáticos (MILLER, 2007). Sua técnica busca um processo criativo, baseado na improvisação e na consciência corporal, buscando o autoconhecimento do corpo e a expressão pelo movimento.

A educação somática não se prende à utilização de espelhos durante a aula, se diferencia, assim, das tradicionais salas de dança, onde prevalecem movimentos homólogos e padronizados, rotulando a movimentação singular e própria de cada pessoa. Nas aulas de educação somática, a intenção é fazer com que o aluno seja o protagonista do seu próprio movimento sem haver cópias e mecanização, possibilitando que o aluno descubra novas formas de se mover respeitando seu corpo e seus limites. Sendo assim, a educação somática fornece ao aluno o abandono de hábitos posturais inadequados, desequilíbrios musculares, automatismos, pois o aluno aprende uma nova forma de sentir e movimentar o corpo. Nas aulas de somática também estão presentes vários objetos auxiliares (bolas, bastões, rolos) que são usados como forma de massagem, relaxamento e favorecem o aumento da percepção corporal. A respiração é outro elemento muito presente nas aulas, pois fornece o silêncio corporal, através da observação da sua própria respiração, capacitando o aluno a conectar a respiração com a movimentação.

Nesse sentido, a educação somática proporciona a ampliação do repertório corporal por meio da sensibilidade e percepção do corpo, conduz o indivíduo a descobrir seu corpo, e acessar caminhos corporais nunca experimentados, assim, ele "aprende a tomar suas próprias sensações como referência do aprendizado" (BOLSANELLO, 2005, p.103). Além de fomentar o desenvolvimento da sensibilidade, a prática deve proporcionar também o aprendizado do sujeito sobre si mesmo, o conhecimento corporal e a capacidade de decidir, de escolher o melhor caminho de agir e de se movimentar nos vários âmbitos da vida cotidiana.

\section{Vivenciando a dança}

A dança pode ser considerada uma linguagem projetada através da expressão corporal, uma das formas de comunicação do homem com o mundo a sua volta, constituída por uma interpretação subjetiva de cada pessoa (LINDNER; ROSSINI, 2013). No contexto contemporâneo a dança vem buscar novas formas de movimentação, de estruturação do corpo e de expressão de sentimentos, em que a criação de movimentos por meio da improvisação se torna característica marcante.

A vivência da dança é um importante meio para o desenvolvimento da conscientização e percepção corporal. Assim como é importante que ao dançar a pessoa esteja consciente da sua movimentação, perceba o seu corpo no espaço e sua relação com as pessoas a sua volta. A partir dessa consciência a pessoa é capaz de conhecer o seu próprio corpo, suas possibilidades e limitações. Sendo assim, o trabalho com a consciência corporal é de suma importância na 
dança, pois oferece a compreensão dos movimentos e seus significados, como o movimento acontece e porque ele acontece: "é a consciência do corpo na dança que condiciona o próprio destino do movimento, transformando-o em movimento dançado" (GIL, 2001, p. 135).

Segundo Miller (2012, p. 67), na improvisação, "o movimento aparece como vetor de emoções, não a emoção criada, narrada, interpretada e representada, mas a emoção como consequência das memórias e sensações que se instauram e instabilizam o corpo em moção". Assim, a improvisação proporciona a exploração e a experimentação do próprio corpo, a partir das perspectivas de suas culturas corporais e experiências pessoais. Logo, uma sequência de movimentos se diferencia de uma pessoa para outra, em relação às formas, fluências, ritmo, pesos, fazendo parte da característica pessoal de cada um, propondo uma dança única para aquela pessoa, exalando sua singularidade.

O contato improvisação é uma técnica de dança que surge também com a perspectiva de explorar os movimentos corporais e sensitivos por meio da criação e do contato corporal com os participantes, sem o estabelecimento de movimentos padronizados (KLEINUBING, 2008). No contato improvisação é como se todos os corpos constituíssem um só corpo, baseado na aceitação, confiança e na entrega corporal. Além disso, estabelece-se uma relação de respeito, cuidado e responsabilidade consigo e com o outro, que envolve aprender a dar e receber o peso, relaxar, seguir pontos de contato, cair, rolar; relacionando-se assim "à consciência corporal, à percepção e observação dos limites físicos, à espontaneidade, à generosidade, ao prazer, à liberdade, à inclusão e à cooperação" (LEITE, 2005, p. 107). A entrega e a confiança dos parceiros no Contato e Improvisação devem ser profundas, para que os corpos consigam entrar em um diálogo comum, entre perguntas e respostas, a ponto de os corpos conseguirem identificar os próximos movimentos a serem executados. Por meio dessa conexão, Gil (2001, p. 136) afirma:

[...] Os corpos deslizam uns sobre os outros, enrolam-se, lançam-se uns sobre os outros, rolam por terra, ficam costas com costas, etc. Todo o movimento se origina no peso e no equilíbrio dos corpos ou antes no desequilíbrio iminente das posições: o movimento de um bailarino cria essa pergunta à qual o corpo do outro dará uma resposta segundo a inclinação do peso e da energia que lhe convier melhor. A energia deve deslizar, o movimento fluir o mais facilmente possível [...].

A principal forma de comunicação que o contato improvisação estabelece é através da sensibilidade da pele, pelo contato e pela pressão entre todas as partes do corpo, ampliando a atenção para o corpo inteiro. "A pele é uma referência para a estimulação sensorial e motora na organização da postura, do equilíbrio e da motricidade" (TEIXEIRA, 2000, p. 257-8), portanto, por meio do contato com a pele, a pessoa desenvolve sua consciência corporal, a propriocepção, a atenção, criando um corpo perceptivo às sensações, um corpo disponível à escuta de si e do outro.

A partir desses pressupostos, foram desenvolvidas no projeto dinâmicas que buscam proporcionar um elo de comunicação entre a educação somática e as técnicas de improvisação e contato improvisação. Assim, destacam-se os jogos de exploração através dos sentidos; a criação de movimentos a partir de diferentes direções, planos e eixos; o trabalho com objetos de diferentes texturas, pesos, formas; a comunicação dos sentidos por meio do contato; e outras dinâmicas corporais que envolvem a criação de um corpo dançante. Segundo Leal (2006, p. 76), "criar em busca da expressão é um dos fundamentos para a arte de dançar". Busca-se, assim, explorar a criatividade através de expressões corporais, seguindo propostas de improvisação e composição, para que o aluno execute o movimento de forma consciente, e não realize somente a mera execução de passos.

Nesse sentido, o trabalho com a improvisação e o contato improvisação podem proporcionar novas ferramentas de exploração sensorial do corpo. Isso abre novas possibilidades 
de trabalhar o campo da educação somática por meio de jogos e dinâmicas dançantes, proporcionando aos participantes explorar o aspecto lúdico, a criatividade, desenvolvendo as relações intrapessoais e interpessoais.

\section{Resultados e discussão}

\section{A escuta do corpo e a escuta do outro}

Para escutar é necessário estar atento ao momento presente, estar com a capacidade perceptiva aguçada e sensível para receber os estímulos e poder interpretá-los. A sensibilidade pode ser compreendida em uma relação dialógica, "que toca e se deixa tocar, que afeta e se deixa ser afetado no seu modo de ser e estar no mundo [...] se refere à abertura para sentir o outro e, nisso, também se deixar sentir" (FIAMONCINI, 2015, p. 60). Dessa maneira, a sensibilidade nos permite obter as sensações e reconhecê-las para então aprender sobre elas, refletir sobre elas.

Diante desses pressupostos procuro identificar nesse primeiro item quais foram as sensações e percepções manifestadas pelos participantes. Sendo assim, a sensação de grande destaque nas entrevistas com relação às dinâmicas da educação somática foi o relaxamento, a sensação de leveza e tranquilidade, como podemos observar nas falas a seguir: "[...] Me traz uma sensação maravilhosa de descanso, a tensão, aquilo alivia, dá uma soninho, acalma, acalma mesmo"; "O relaxamento, a gente se sente bem mais relaxado, a gente sente que a musculatura se solta [...]."

Segundo Imbassaí (2003), o relaxamento é essencial nas aulas que envolvem a consciência corporal, pois irá permitir que o corpo esteja disponível para despertar as sensações, uma disponibilidade de unicidade corporal, orgânica.

Nas anotações do diário de campo, a percepção com grande relevância destacada, após as dinâmicas somáticas, também foi a sensação de relaxamento que teve como consequência o alívio de tensões em alguns participantes.

Após as dinâmicas de educação somática, muitos alunos relataram sentir diferença entre o membro que foi trabalhado e o que não foi trabalhado. As principais sensações manifestadas eram de expansão, relaxamento e leveza. Muitos alunos manifestaram sentir aliviar tensões e dores no corpo durante as dinâmicas, percebendo quais os locais do corpo onde a dor se manifestava (DIÁRIO DE CAMPO, 2016).

A dor foi outra questão muito enfatizada nas entrevistas, em que os participantes relataram a percepção da dor em seu corpo e também a melhora dessas dores e tensões por meio das dinâmicas somáticas.

Tinha mais dor na perna, agora aliviou a dor na perna, a dor no braço, já estou levantando melhor, talvez por causa das aulas melhorou um pouco. Da bursite que eu tenho melhorou um pouco, eu acho que essas atividades possam ter melhorado, porque eu não tomei remédio para melhorar, eu não fiz nenhum tratamento, eu acredito que seja os exercícios. (VARGAS, 2016)

Eu sinto melhora no meu corpo, melhora nas dores, eu tenho bastantes dores às vezes, reumáticas, e passa com os exercícios [...], não gemer para tudo, [risos] ou sem vontade para fazer as coisas, disposição para fazer as coisas, porque as coisas ficam mais fáceis, o corpo fica mais leve, apesar de o peso ser o mesmo, mas o corpo fica mais leve. (DAVILA, 2016)

Podemos observar que as dinâmicas de educação somática tiveram grande influência sobre as dores dos participantes, proporcionando o alívio e a melhora das dores, consequen- 
temente, proporcionando maior bem-estar. Para Bolsanello (2005), a educação somática poderá atuar em diferentes necessidades, como, por exemplo, na diminuição de sintomas antálgicos, na recuperação do esgotamento físico e mental, na respiração, no relaxamento de tensões excessivas e na ativação de músculos pouco utilizados, dentre outros, podendo intervir tanto na patologia quanto na prevenção.

A respiração foi outro elemento que apareceu com bastante destaque nas falas dos participantes, como podemos observar a seguir.

Quando ela [arritmia] começa eu faço os exercícios de respiração e tenho sentido que passa, para mim tem sido ótimo, [...]. Uso bastante os exercícios e sinto que houve resultados [...]. (DAVILA, 2016)

E a respiração ela ajuda muito, em você se acalmar, até quando tem alguma dor, algum desconforto, você faz um exercício respiratório, você dá um passo à frente, libera a tensão. (ARGENTA, 2016)

De acordo com Miller (2007, p. 64) quando o aluno toma percepção de suas dores, tensões musculares, o conhecimento de quais articulações estão limitadas e como desbloqueálas, isso oportuniza maior liberdade de movimentação. Assim, de acordo com a necessidade e a particularidade de cada pessoa, a educação somática poderá trazer resultados eficazes na saúde, proporcionando bem-estar geral.

Segundo Imbassaí (2003, p. 55), a percepção deve estar presente no cotidiano, devemos perceber como os nossos sentidos se relacionam com as nossas tarefas diárias a serem cumpridas, por mais simples que sejam "as ações cotidianas, como caminhar, tomar banho, pentear-se, falar ao telefone, escrever/digitar, andar de metrô [...], podem se transformar em excelentes exercícios de percepção gustativa, olfativa, tátil, auditiva e visual. Para isso basta estarmos conscientes e sensíveis [...].” Assim, as relações entre a percepção corporal com a vida diária apareceram fortemente nas entrevistas, como podemos analisar a seguir.

\footnotetext{
Sim, trouxeram bastante mudanças, eu uso esses exercícios às vezes quando tenho alguma dor em casa, tento usar com a bolinha, e, também a de respiração, além de problemas articulares [...]. Quando eu me sinto com arritmia eu tento fazer esses exercícios de respiração e vai passando devagar, quando não é muito forte [...]. Uso bastante os exercícios e sinto que houve resultados [...] (DAVILA, 2016).

De começar a observar os meus membros, a questão da postura a gente tenta se policiar no sentar, a maneira como você senta, para fazer alguma atividade ou até para você assistir uma televisão, uma coisa assim, você tem que estar se policiando e quando vê você está torta. (SANTOS, 2016).
}

A partir das falas é possível observar que as participantes conseguiram ampliar a sua percepção corporal e propagar essa percepção para a vida cotidiana, podendo perceber o seu corpo, a sua postura, as dores, tensões e assim poder ter autonomia para autorregular o seu corpo. Dessa forma, a relação entre a sensibilidade e a consciência não permaneceu somente dentro da sala, sendo transferida para as questões da vida diária. Para Imbassaí (2003), essa é uma das principais propostas do trabalho com a consciência corporal, fazer com que o aluno seja capaz de identificar suas tensões, dores e desconfortos para proceder à regulagem das mesmas, estimulando assim a propriocepção. Dessa forma, é muito significativo que os alunos consigam transferir os conhecimentos adquiridos nas aulas de educação somática para as situações da vida cotidiana e possam reconhecer as melhoras e os aprendizados que as vivências oportunizaram.

Segundo Bolsanello (2005), é muito importante que o professor, ao trabalhar com a educação somática, desperte a atenção do aluno para que possa se concentrar no movimento proposto, evitando um comportamento automático e ausente. A consciência de um corpo integrado é de suma importância para qualquer prática corporal, percebendo como os ossos, mús- 
culos, articulações, respiração e outros sistemas interagem de forma integrada durante a atividade. No contrário, quando a pessoa está inconsciente de seu corpo durante a prática ou se submete a um esforço exagerado, o risco de lesões, contraturas e estresse aumenta, afetando o funcionamento normal e harmonioso do organismo.

Esse estado perceptivo é muito enfatizado na fala da Zenilda Santos, ao afirmar que durante uma prática você deve estar presente de "corpo e alma", ou seja, atuando com seu corpo integrado para que essa prática corporal possa oferecer benefícios no seu corpo como um todo.

Para você fazer, você tem que estar ali, de corpo e alma, senão você não consegue, fica uma coisa automática e não tem efeito nenhum [...] problemas, preocupações tem de sair tudo, a tua cabeça tem que estar bem leve e a mente livre, naquele momento a gente tem que estar só ali, o que você está orientando, na orientação e no movimento. E acalma, você sai mais leve. (SANTOS, 2016)

Escutar o corpo se faz muito importante nesse processo da consciência corporal, pois é por meio da escuta que vamos aprofundando nossa percepção e consequentemente o reconhecimento de um corpo integrado e total. Bolsanello (2011) enfatiza que, à medida que a pessoa adquire um conhecimento do seu corpo e toma consciência das suas movimentações, ela desenvolve uma capacidade de autorregulação, ou seja, de reconhecer o mal-estar, o desequilíbrio corporal e assim poder reorganizar e restaurar o equilíbrio do corpo novamente.

\title{
A dança da vida: "livre, leve e solto"
}

\begin{abstract}
Para mim a dança é liberdade [...]. É liberdade de expressão, liberdade de movimento, principalmente quando é aquela dança que não tem que seguir nada, tu faz a tua dança, essa dança aí é a que eu mais gosto, que eu acho que ela liberta tudo o que está dentro, tu põe pra fora. Me lembro uma vez que nós fizemos um círculo, e cada um dançava do seu jeito, eu comecei a dançar ali assim, e de repente eu não vi mais ninguém, e comecei a dançar, dançar, dançar... (LEMOS, 2016).
\end{abstract}

A dança quando executada de uma forma espontânea e criativa se aproxima dos princípios da improvisação. A dança na improvisação possibilita a experimentação criativa e diversificada dos movimentos, como também oportuniza a construção de movimentos baseados nas experiências e histórias de vida dos alunos, e permite que as questões da vida cotidiana se façam presentes nas escolhas e criações dos alunos (PICCININI, SARAIVA, 2012). Assim, na improvisação, o movimento não chega codificado e padronizado, mas é construído a partir da linguagem corporal de cada aluno, exalando a criatividade, a imaginação, aliada a princípios libertadores e não repressores.

Assim, a improvisação foi um elemento muito forte trabalhado nas aulas, e foi um dos momentos em que os participantes mais se sentiram à vontade para dançar. A improvisação nas aulas era voltada para aumentar a capacidade criativa de cada aluno, buscar novas possibilidades de movimentação e também novas possibilidades de expressão corporal. De acordo com Leal (2006, p. 76), "a criatividade não pode ser esquecida. E dançar, antes de tudo, é expressar-se. Não apenas mera execução de passos. [...] Criar em busca da expressão é um dos fundamentos da arte de dançar". Por meio das dinâmicas que envolviam improvisações buscava-se ampliar o repertório corporal de cada participante, ir além da reprodução de passos e movimentos pré-determinados e, assim, ampliar o olhar dos participantes para o que vem a ser a dança. 
Eu sempre gostei de dançar, essas danças que você faz que bota uma pessoa dançar no meio, eu acho maravilhoso, de a pessoa está podendo dançar como ela quer, está podendo dançar livre [...] acho que a pessoa vai nas alturas [...] (GOULART, 2016).

Observa-se nos depoimentos que as participantes preferem dançar quando entram em contato com a improvisação, quando não precisam seguir passos padronizados, mas quando realizam sua "própria dança", quando conseguem se expressar corporalmente da sua maneira, do seu jeito de ser e viver no mundo, aflorando sua personalidade e singularidade por meio de uma singela dança.

Ao mesmo tempo em que os participantes gostam de improvisar, a dança encontra-se ainda fechada e padronizada para alguns participantes, sendo difícil sair da reprodução de movimentos e obter um olhar mais abrangente para a dança. Dessa forma, se faz importante destacar uma reflexão anotada no diário de campo acerca da pouca experiência e contato dos participantes com novas movimentações e formas de se expressar corporalmente.

Durante as dinâmicas de criação, alguns apresentam dificuldade de criar movimentos. Normalmente quando peço para criarem algum movimento, eles fazem posições de algum alongamento, exercícios físicos. Porque foi apenas esses movimentos que fizeram parte do vocabulário corporal deles durante o contato com as práticas corporais. Falta diversidade, o conhecimento de novas movimentações, descontruir o padrão. (DIÁRIO DE CAMPO, 2016).

Em relação aos sentimentos e sensações que a dança manifestou nos participantes podemos destacar os sentimentos de prazer, bem-estar e alegria, como pode ser identificado nas falas a seguir: "[...] o movimento também melhora a pessoa, a dança (LEMOS, 2016)"; "a sensação é boa de a gente dançar, eu me sinto bem (VARGAS, 2016)"; "eu me sinto mais contente mais alegre, com a dança eu me sinto bem, eu adoro dançar [...]" (DAVILA, 2016). Para Soares (2013) as sensações de bem-estar e prazer são aspectos facilitadores para poder experienciar a ludicidade durante uma prática. Sendo assim, as vivências com a dança nas aulas tiveram profunda conexão com o aspecto lúdico.

Nas falas a seguir também podemos analisar a aproximação da dança com o aspecto lúdico, em que se evidencia a questão da socialização e da convivência com o próximo.

As aulas com música e com dança eu gosto bastante, e eu sinto no grupo como um todo, como está o envolvimento e uma reciprocidade também entre os diferentes alunos, você brinca, a gente tem alguns movimentos que você toca mais, outros toca menos, e você vai, acaba tornando uma brincadeira, divertida, e eu acho que isso é bem legal (WARREN, 2016).

Luckesi (2005) afirma que a socialização potencializa o lúdico que essa prática pode proporcionar. Por meio dessas falas podemos perceber que a dança resgata sensações de felicidade e de convivência com o próximo, mantendo profunda conexão com a ludicidade.

\section{Considerações finais}

O corpo é inerente ao ser humano, não é apenas matéria e instrumento de uso; o corpo sente, fala, se expressa, é por meio do corpo que obtemos experiências.

Assim, é através dessa concepção de corpo e de visão do ser humano que as aulas do projeto buscaram abordar a totalidade e a integração das várias dimensões que constituem o nosso corpo. Dessa forma, a educação somática e a dança vêm reafirmar essa integralidade do corpo que atualmente está se perdendo, fazendo florescer características singulares e particulares de cada pessoa. 
Sendo assim, por meio da análise das entrevistas e das anotações do diário de campo, podemos perceber que as vivências de educação somática despertaram nos participantes a sensação de relaxamento, tranquilidade, estando fortemente relacionadas ao alívio de tensões e dores, sendo que essas práticas somáticas foram utilizadas pelos participantes no dia a dia, em suas casas, para autorregularem suas dores e outros problemas de saúde particulares. Desse modo, foi identificado nas falas que a massagem e automassagem foram fortemente utilizadas pelos participantes e tiveram resultados eficazes para diversos problemas corporais, assim como ocorreu com a respiração, que contribuiu para amenizar as dores, o estresse, as tensões, e até mesmo problemas cardíacos, como arritmia.

Em relação à dança desenvolvida no projeto, pode-se notar que a improvisação teve grande destaque nas falas dos participantes. As improvisações permitiram que os participantes criassem movimentos diversificados, explorando a criatividade, o seu jeito de se expressar corporalmente, despertando sentimentos de prazer, felicidade e bem-estar.

Assim, pode-se perceber a forte relação da educação somática no desenvolvimento da consciência corporal dos participantes, levando as experiências e aprendizados para a vida diária, pois por meio da consciência do corpo e do movimento o aluno se torna capaz de ser o próprio veículo de mudança corporal, desenvolvendo assim a autorregulação e autonomia de suas ações motoras.

Por fim, acreditamos que as dinâmicas de educação somática e os elementos da dança oferecidos no projeto proporcionaram a construção de um corpo perceptivo e consciente, possibilitaram ao corpo a capacidade de reflexão sobre as práticas corporais e as questões que se processam na dinâmica da vida. Dessa forma, esperamos ter contribuído para a construção de um corpo integrado e consciente, não somente durante as práticas corporais, mas também durante a vida cotidiana, valorizando as singularidades de cada participante, pois cada ser humano é único e tem um lugar especial no mundo.

\section{Referências}

ARGENTA, M. C. M. Mercedes C. M. Argenta: depoimento [jul. 2016]. Entrevista concedida a Nicole da Rosa Cachoeira para o Trabalho de Conclusão de Curso. Florianópolis, Universidade Federal de Santa Catarina - UFSC, 2016.

BARDIN, L. Análise de Conteúdo. Lisboa: Edições 70, 2009.

BOLSANELLO, D. Educação somática: o corpo enquanto experiência. Motriz, Rio Claro, v. 11, n. 2, p. 99-106, 2005.

. A educação somática e os conceitos de descondicionamento gestual, autenticidade somática e tecnologia interna. Motrivivência, Florianópolis, v. 23, n. 36, p. 306-322, 2011.

BONETTI, A. O coração e o lúdico: vivências corporais para um viver mais saudável de pessoas com problemas cardiovasculares. 2006. 212 f. Tese (Doutorado em Enfermagem)Programa de Pós Graduação em Enfermagem, Centro de Ciências da Saúde, Universidade Federal de Santa Catarina, Florianópolis, 2006.

BONFIM, T. R. Coporeidade e educação física. Revista Fafibe online, Bebedouro, v. 1, n. 1, p. 1-6, jul. 2005. Disponível em: 
$<$ http://unifafibe.com.br/revistasonline/arquivos/revistafafibeonline/sumario/9/180520111404 24.pdf>. Acesso em: 23 maio 2016.

DAVILA, M. A. S. Maria Amélia S. Davila: depoimento [jul. 2016]. Entrevista concedida a Nicole da Rosa Cachoeira para o Trabalho de Conclusão de Curso. Florianópolis, Universidade Federal de Santa Catarina - UFSC, 2016.

FREIRE, I. M.; DANTAS, M. H. A. Educação e corporeidade: um novo olhar sobre o corpo. Holos, Rio Grande do Norte, v. 4, n. 28, p. 148-157, 2012.

IMBASSAÍ, M. H. Conscientização corporal, sensibilidade e consciência no mundo contemporâneo. In: CALAZANS, J.; C. J.; GOMES, S. (Org.). Dança e educação em movimento. São Paulo: Cortez, 2003. p. 47-57.

FIAMONCINI, L. Sensibilidade na formação do professor: experiências na educação física. 2015. 139 p. Tese (Doutorado em Educação Física)-Centro de Desportos, Universidade Federal de Santa Catarina, Florianópolis, 2015.

GIL, J. Movimento total - O corpo e a Dança. Lisboa: Relógio D’Água, 2001.

GOULART, A. L. Alaide L. Goulart: depoimento [jul. 2016]. Entrevista concedida a Nicole da Rosa Cachoeira para o Trabalho de Conclusão de Curso. Florianópolis, Universidade Federal de Santa Catarina - UFSC, 2016.

KLEINUBING, N. D. Experiências em dança: possibilidades de transformação da imagem corporal do corposurdo. In: XAVIER, Jussara; MEYER, Sandra; TORRES, Vera (Org.). Coleção dança cênica: pesquisas em dança. 1. ed. Joinville: Letradágua, 2008.

LEITE, F. H. D. C. Contato improvisação (contact improvisation) um diálogo em dança. Movimento, Porto Alegre, v. 11, n. 2, p. 89-110, maio/ago. 2005.

LEAL, P. Respiração e expressividade: práticas corporais fundamentadas em Grahan e Laban. 1. ed., São Paulo: Annablume, 2006.

LEMOS, E. Z. Elzira Z. Lemos: depoimento [jul. 2016]. Entrevista concedida a Nicole da Rosa Cachoeira para o Trabalho de Conclusão de Curso. Florianópolis, Universidade Federal de Santa Catarina - UFSC, 2016.

LINDNER, M. K.; ROSSINI, I. S. Dança como linguagem corporal. Caminhos, Rio do Sul, v. 4, n. 7, p. 19-27, jul./set. 2013.

LUCKESI, C. C. Ludicidade e atividades lúdicas: uma abordagem a partir da experiência interna. Coletânea Educação e Ludicidade - Ensaios 02, GEPEL, Programa de PósGraduação em Educação, Salvador, n. 2, p. 22-60, 2005.

MILLER, J. A escuta do corpo: sistematização da Técnica Klauss Vianna. São Paulo: Summus, 2007.

Qual é o corpo que dança? Dança e educação somática para adultos e crianças. São Paulo: Summus, 2012. 
MARKONDES, E. Dança e educação somática: uma parceria para o movimento inteligente. In: XAVIER, Jussara; MEYER, Sandra; TORRES, Vera (Org.). Coleção dança cênica: pesquisas em dança. 1. ed., Joinville: Letradágua, 2008.

PICCININI, L.; SARAIVA, M. D. C. A dança-improvisação e o corpo vivido: ressignificando a corporeidade na escola. Pensar a prática, Goiânia, v. 15, n. 3, p. 551-820, 2012.

SANTOS, Z. M. O. Zenilda M. O. Santos: depoimento [jul. 2016]. Entrevista concedida a Nicole da Rosa Cachoeira para o Trabalho de Conclusão de Curso. Florianópolis, Universidade Federal de Santa Catarina - UFSC, 2016.

SOARES, D. T. Ludicidade como estados do corpo: a arte do palhaço imbricada na dança. In: III ENCONTRO CIENTÍFICO NACIONAL DE PESQUISADORES EM DANÇA. 2013, Salvador. Anais... Salvador: Universidade Federal da Bahia, 2013. p. 1-16.

TEIXEIRA, L. Angel Vianna: a construção de um corpo. In: PEREIRA, R.; SOTER, S. (Org.). Lições de dança 2. Rio de Janeiro: UniverCidade, 2000. p. 247- 264.

VARGAS, F. P. Flor P. Vargas: depoimento [jul. 2016]. Entrevista concedida a Nicole da Rosa Cachoeira para o Trabalho de Conclusão de Curso. Florianópolis, Universidade Federal de Santa Catarina - UFSC, 2016.

WARREN, I. S. Ilse S. Warren: depoimento [jul. 2016]. Entrevista concedida a Nicole da Rosa Cachoeira para o Trabalho de Conclusão de Curso. Florianópolis, Universidade Federal de Santa Catarina - UFSC, 2016.

Recebido em: 17/06/2017

Revisado em: 23/04/2018

Aprovado em: 21/05/2018

Endereço para correspondência:

nicolecachoeira@gmail.com

Nicole Rosa Cachoeira

Universidade Federal de Santa Catarina

Departamento de Educação Física -Campus Universitário,

Trindade 88040-900, Florianópolis, SC 